\title{
The Effectiveness of Distance Education in Ghana
}

\author{
Mends-Brew Edwin ${ }^{1}$, Asabere Nana Yaw ${ }^{2}$ \\ ${ }^{1}$ Department of Mathematics and Statistics, Accra Polytechnic, Accra, Ghana \\ ${ }^{2}$ Department of Computer Science, Accra Polytechnic, Accra, Ghana \\ Email address: \\ emendsbrew@yahoo.com (Mends-Brew E.),nyasabere@apoly.edu.gh (Asabere N. Y.)
}

\section{To cite this article:}

Mends-Brew Edwin, Asabere Nana Yaw. The Effectiveness of Distance Education in Ghana. Science Journal of Applied Mathematics and Statistics. Vol. 4, No. 4, 2016, pp. 159-167. doi: 10.11648/j.sjams.20160404.16

Received: June 24, 2016; Accepted: July 5, 2016; Published: July 28, 2016

\begin{abstract}
Distance Education (DE) focuses on the pedagogy, technology, and instructional system designs that seek to deliver education to students who are not physically present "on site" in a traditional classroom or campus. The introduction of new educational technologies has brought in its wake a pedagogical shift in higher education. Emerging technologies especially in Information and Communication Technology (ICT) have unleashed new opportunities and frontiers in higher education for a countless number of the populace who otherwise would have had no access to tertiary education. Essentially, the study sought to determine the Effectiveness of Distance Education Programmes in the Ghanaian school system, the contribution DE has made in improving quality and accessibility to higher education in Ghana and the benefits derived from $\mathrm{DE}$ as well as providing a platform for improving productivity in both public and private sectors of the economy. The study made use of primary data collected using stratified random sampling procedure. The data was extensively analyzed using graphs and tables as well as chi-square test of goodness-of-fit. The results showed that, DE has improved quality and accessibility to higher education culminating in significant improvement in productivity levels in both public and private sectors of the economy over the last several years. Access to tertiary education, convenience, flexibility and improved knowledge and employee efficiency are the ultimate benefits derived from Distance Education programmes. Empirically, the study also established that Distance Education has been effective in the Higher Education Enterprise in Ghana.
\end{abstract}

Keywords: Distance Education (DE), Effectiveness, Higher Education Practice, Information and Communication Technology (ICT), Tertiary Education, Accessibility

\section{Introduction}

According to Honeyman and Miller (1993) [17], Distance Education (DE), or Distance Learning, is a field of education that focuses on the pedagogy, technology, and instructional system designs that aim to deliver education to students who are not physically present "on site" in a traditional classroom or campus. It has also been described as "a process to create and provide access to learning when the source of information and the learners are separated by time and space, or both [17].

In Ghana, the idea of Distance Education (DE) started more than three decades ago [18]. However, it was repackaged and re-launched in the 1990s. Distance education has evolved since the last century, [29] from very modest beginnings to a more sophisticated and wed based environment. It has had a chequered history which spans over several decades [19]. In its earlier phase, it was best described as correspondence education, [32] because instructors and tutors taught students at a distance, separated by space and or time through the postal mailing platform. With the dawn of the new century, modern technological innovations have gradually modified the practice significantly with impressive outcomes [14].

Additionally, as new modes of interactions are discovered with the unfolding of new technologies, new definitions and interesting trends in Distance Education equally emerge as well. This is supported by Garrison, Randy D. (1997) [10] who argues that; modern technological advancement such as audio-conferencing, videoconferencing, or computer conferencing at scheduled times make instant interactive teaching and learning sessions possible with the separation of the instructor and the learner.

The mission of Ghana's Distance Education programme is 
to make quality higher education at all levels, more accessible and relevant to meet the learning needs of all Ghanaians in order to enhance their professional competence and improve the quality of their lives. "While distance learning is not likely tocompletely replace delivery of traditional instructions in tertiary institutions, technologybased training programmes are growing rapidly [2]. Emerging technologies, especially in Information and communication Technologies (ICTs) have unleashed new opportunities and frontiers in higher education for countless number of the populace who otherwise would have had no access to education. The massive deployment of information technologies has provided educators with resources that have the potential to reach countless number of students. For example, Internet-based distance learning is currently one of the fastest growing markets in the education enterprise [25]. The expanding use of technology challenges traditional classroom and instructional models of how successful training and learning, should be administered as espoused eloquently by Asabere, N. Y. et al (2012) [1].

According to Wulf, Katie (1996) [35], the advent of the Internet has pushed learning beyond the boundaries of the classroom. Over the last two decades, virtual learning environments have emerged to supplement the traditional educational system. These involve a set of teaching and learning tools designed to specifically enhance a student's learning experience by including computers and the Internet in the learning process. Moreover, the rich technology era has led to the emergence of a virtual learning environment that underpins contemporary distance education programmes encompassing but not limited to the deployment of the following; electronic communication using e-mail, internet relay chat, threaded discussions, online support, and links to web resources (special students portals etc). According to Taylor, J. C. (2001) [32], the delivery platform within this environment is driven by information technology. This may range from the use of audio, video, multimedia CD-ROM, to developing websites for courses and placing them on the internet, with links to databases and related sites or course intranet with portals created for consolidating course information from several sources [5]. Additionally, the use of proprietary learning management systems such as the open source Moodle, Blackboard, ANGEL and WebCT now dominate the online learning software market [8]. With these huge investments in education technology, it is expected that virtual learning environment will certainly dominate the traditional classroom. Current trends in higher education show that entire programmes have been placed on the internet [42]. It is thus evident that the transition from the traditional classroom to a mix mode to a complete online programme has significantly gained momentum over the last several years [1]. It is now possible to obtain a degree without ever having to leave the exclusive comfort of one's precincts. The remainder of the paper is organized as follows: The ensuing section presents briefly an overview of the evolution of Distance Education in Ghana. This is followed by a review of empirical literature pertaining to the study. Section 4 essentially deals with the discussion of the methodology employed in conducting the research. Results are subsequently presented and discussed in section 5 . The paper ends with drawn conclusions in section 7 .

\section{The Evolution of Distance Education (DE) in Ghana}

Ghana has six (6) publicly funded universities, ten (10) polytechnics and about fifty (50) private universities including thirty eight (38) colleges of Education. These institutions have provided the avenue for the training of professionals and other technocrats for both the private and public sectors of the economy. However, these institutions, though quite considerable, are not adequate to sufficiently absorb all high school graduates together with a cross section of the Ghanaian workforce who intend to build on their respective human capacities. For the past years, Ghana's premier universities have had the unpleasant task of having to turn away a large number of equally qualified applicants every single year as a result of their inability to admit less than a third of these applicants [26]. Thus, making access critical and limited to only a few. Therefore, traditional approaches based on conventional classroom-based teaching and learning will not be capable of meeting the escalating demand for higher education and professional development [32]. It is against this backdrop that some tertiary institutions have sought for both national and international assistance with the evident support of the Ministry of Education (MoE) and implemented Distance Education (DE) Programmes with a huge ICT support base. This is supported by Ghana's educational policy which emphasizes on the promotion of DE programmes to essentially increase access to education at all levels and ultimately facilitate human capital development [27].

This paper focuses on how effective these programmes have been since their inception and some of the factors that have necessitated and contributed to the introduction and implementation of Distance Education programmes. At the apex of these myriads of problems is the fact that existing structures and facilities provided are limited and are therefore subjected to undue pressure due to competing demands by users. Secondly, the high demand for tertiary education is not adequately matched by existing tertiary institutions in Ghana due to population growth. Coupled with these limited facilities is the rising cost of providing quality education at the tertiary level. According to Asabere, N. Y et al (2012) [1], the Government of Ghana finds it increasingly difficult to fund tertiary education single handedly. It is in recognition of these inadequacies that $\mathrm{DE}$ has been adopted as a viable complement to the conventional mode of teaching and learning in fulfillment of the vision that every Ghanaian should have access to education regardless of where they live and irrespective of the mode of delivery.

Kwapong (2010) [23], shares the views of Asabere, N. Y et al (2012) [1] that distance education is seen as a solution to the challenges facing conventional education by tackling 
the primary problems of space and infrastructure as well as widen access to tertiary education. Thus, creating an opportunity for work and study, enhance access to participation in education at all levels especially tertiary education, promote equality and equity in education, provide cost-effective and affordable education and eventually, serve as an avenue for financial resource mobilization for these public tertiary institutions among others.

\subsection{Distance Education (DE) Practice in Tertiary Institutions}

\subsubsection{The Institute of Distance Learning (IDL)-KNUST, Kumasi}

The Institute of Distance Learning (IDL) at the KNUST was initially established as the Faculty of Distance Learning (FDL) in 2005 in response to the demand for tertiary education outstretching the limited resources of Ghana's Higher Educational Institutions. Since its inception, IDL has been offering both undergraduate and postgraduate programmes to the general public through DE. In fulfilling its avowed goal of making Science and Technology Education accessible to the citizenry of the nation, it has 13 different learning centres established across towns and cities in the various regions of Ghana with a student population of 10,000. The Accra and the Kumasi centres provide the bulk of the institutions share of patronage by students. Currently, the IDL runs 17 undergraduate programmes across the academic spectrum from the various departments of the University in addition to 13 postgraduate programmes. [36].

\subsubsection{Programmes Offered by IDL, KNUST}

The IDL offers both undergraduate and postgraduate programmes. Undergraduate programmes, currently being run by the Institute include the following; BSc. Computer Engineering, BSc. Building Technology, BSc. Quantity Surveying \& Construction Economics, BSc. Construction Technology \& Management, BSc. Actuarial Science, BA Sociology \& Social Work, BSc. Electrical and Electronic Engineering, BSc. Telecommunication Engineering and BSc. Computer Science. Additionally, the postgraduate programmes currently run by IDL include but not limited the following: Commonwealth Executive Master of Business Administration (CEMBA), Commonwealth Executive Master of Public Administration (CEMPA), MSc. Industrial Mathematics, MSc. Postharvest Technology (Horticulture) and MSc. Environmental Science.

In keeping with its Strategy Plan, PLAN2K18, aimed at providing greater access to Science and Technology Education and Training in order to advance Ghana's technological development with the working class as its focus, the institution allows for flexibility in class scheduling to make it flexible and convenient for professionals and other workers to access higher education without hindrance. Besides, the online Virtual classroom affords students further flexibility in choosing between online classes. [36].

The Accra Campus is an Ultra-Modern State of the Art
Technology driven centre using ICT for its programme outreach. While maintaining its time honoured University traditions, the IDL also serves as the University's VIRTUAL CAMPUS coordinating its distance and life-long learning programmes across the country. The Accra Campus of KNUST emphasis is on Applied Sciences and Technology Programmes of Study with a focus on Telecommunications Engineering, Computer Engineering, Electrical Engineering, Biomedical Engineering, Computer Science, Informatics, Computer and Information Technology, Communication Design etc [36].

Increasingly, the IDL continues in its relentless drive to provide greater access to quality tertiary education for the training of needed human capital in the areas of Science and Technology for Ghana's socio-economic growth and industrial development in fulfillment of its vision.

\subsection{Institute of Distance and Continuing Education (IDCE) University of Ghana, Accra}

The Institute of Continuing and Distance Education (ICDE) is one of the key Institutions through which Ghana's premier university carries its presence, mission, standards and curricula into Ghanaian cities, towns and communities. The institution offers courses leading to Diploma, Bachelors, M. A., M. Phil., Ph.D., in Adult education; Youth in Development Work; and short courses for community leaders. In recognition of the significant challenges facing education in Ghana with increasing pressure on limited state resources and to ensure relevancy and equitable access for the growing number of students seeking education at the tertiary level, the role of IDCE cannot be over emphasized since it plays a crucial rule in the country's socio economic development. As technology continues to transform how students are educated, more students resort to Open and Distance Education as the preferred mode of learning [37].

For over 20 years, the IDCE at the University of Ghana has become the vehicle that has conveyed the University of Ghana's rich traditions of teaching, learning, and research into Ghanaian homes. With expanded vision, the Institute has now transformed itself into a more visible, resourceenhanced, dynamic Institute that is responsive in providing lifelong learning opportunities and distance education to all Ghanaians to meet their diverse learning needs for academic, personal, and professional growth. Its mandate re-affirms the University of Ghana's resolve to providing wider and flexible educational access to Ghanaians while maintaining their respective jobs and fulfilling family and other obligations [37].

To advance its central mission to become a centre of excellence for the efficient delivery of university-based continuing and distance education to meet the challenges of national development and global competition, the Institute offers courses leading to Diploma, Bachelors (Arts and Social Sciences), M. A., M. Phil., Ph.D. in Adult Education; Youth in Development Work; and short courses for community leaders. Using interdisciplinary, comparative, gender-sensitive, community-based, interactive learning 
perspectives and technology, the Institute's highly motivated and committed faculty and staff apply their specializations in all fields of study to illuminate the relevance of higher education for empowering individuals, communities, and nations for development and poverty reduction [38].

As the premier Distance Education body in Ghana, the IDCE at the University of Ghana leverages on its strengths in the following areas:

- Research at IDCE covers field studies, evaluation studies, action research and experimental research in all ten (10) regions of Ghana.

- IDCE presently has thirteen (13) Learning Centres in Ghana and extends the resources of the University of Ghana to a wider population of Ghanaians in recognition of their ability to learn regardless of age, sex, religion, ethnicity, place and region of residence.

- IDCE has well qualified and innovative staff from interdisciplinary backgrounds with the ability to collaborate with several departments and organizations and a track record of delivering continuing and adult education in alternative modes and methods. (IDCE, UG, 2006-2008) [37]:

\subsection{College of Distance Education (CODE), University of Cape Coast, Cape Coast}

The College of Distance Education was initially established by the University of Cape Coast as the Centre for Continuing Education (CCE) in 1997. The CODE is an affiliated member of the West African Distance Education Association (WADEA). The CODE, apart from being a subvented sector of the Ministry of Education, maintains active collegial relationship with the sister universities in Ghana and Simon Fraser University of Canada. The Centre was established, primarily, to [39]:

- Provide opportunities for people to pursue higher education; train more professional teachers for all levels of Education in the Ghana Education Service (GES).

- Train high calibre personnel for national development.

- Raise the professional competence of serving teachers and personnel of the Ghana Education Service (GES), as well as accounting and secretarial personnel in civil/public service, commerce and industry through Continuing Education.

- Provide opportunities for applicants who, even though qualify for admission, fail to enter the University due to constraints in physical facilities.

The main focus of the CODE, currently, is directed at [39]:

- Mounting distance education programmes leading to the award of Diploma, Post-Diploma Degree and Master's Degree.

- Mounting all the other viable academic programmes in the University, especially Bachelor of Commerce (B. Com) and Bachelor of Management Studies (BMS) on Distance Education Programme.

- Using the multi-media mode of delivery for its distance education - print, audiovisuals, radio broadcast; television, internet etc.
The CODE has centres in all the regional capitals and some district capitals in the country. It currently has 33 study centres nationwide. These centres form a major component of the administrative structure of the programme. The College is headed by a Director. At the regional centres, there are regional resident tutors. In regions where there are no resident tutors, there are co- coordinators who facilitate the smooth running of the programmes. The main function of these study centres are essentially, to serve as avenues for interaction with staff and students, tutoring and counseling; providing physical facilities such as classrooms, laboratories and libraries for assisting students and organizing lectures; discussion groups, workshops and seminars.

In its quest to providing numerous youth with the opportunity to upgrade their skills and competencies in the hospitality industry in Ghana, the CODE recently introduced two new academic programmes into the DE Curricula; these are the three year degree programmes in Tourism Management and the three year diploma in Hospitality Management [39].

The College of Distance Education has a population of about 41,000 students with the bulk of it coming from the southern districts of the country.

\subsection{The Institute for Educational Development and Extension (IEDE), University of Education, Winneba (UEW)}

The Institute for Educational Development and Extension (IEDE) was established in November 1992 as one of the seven academic divisions of the then University College of Education, Winneba (UCEW), now University of Education, Winneba (UEW). The mandate of the university is to produce professional educators to spearhead a national vision of education aimed at redirecting Ghana's effort along the path of rapid economic and social development. It is also the vision of the university to be an internationally reputable institution for teacher education and research. In keeping with its mandate, the Institute aims at training competent professional teachers for all levels of education as well as conducts research, disseminate knowledge and contribute to educational policy and development [40].

The Institute for Educational Development and Extension, IEDE is the extension wing of the University of Education, Winneba, which is responsible for the distance education programmes of the University. It is also responsible for providing opportunities for student teachers to experience holistic and quality school based teaching experiences as well as providing opportunities for continuing professional development of staff of UEW and professionals from other tertiary and non tertiary educational institutions [40].

Incidentally, the founding of the Institute coincided with the decision of the then British Overseas Development Administration (ODA) which is now, the Department for International Development (DFID) to support quality improvement of education in Ghana in accordance with the Education Reform Programme by assisting with the production of better trained teachers for primary, junior 
secondary and senior secondary schools as well as training colleges in a project known as Support for Teacher Education Project (STEP). IEDE became the base for STEP at UCEW. The DFID through its Support for Teacher Education Project (STEP) provided considerable material assistance to IEDE until the project ended in March 1997, thus enabling it to gain a strong foothold in the growth of Distance Education in Ghana: [40]

Currently, the Institute has an undergraduate student population of 13,145 representing $56 \%$ female and $44 \%$ male. Out of this, 1,424 are Diploma students and 11,721 are Post Diploma (2-Year Bachelor degree) students. In addition, there are 243 graduate students. Increasingly, the IEDE continues to expand with the provision of 24 study centres across the country. Coordinators who are appointed at the same level as University lecturers head these Study Centres. Essentially, they liaise directly with IEDE/UEW and are responsible for the general administration of the Study Centres, thus, giving a human face to the DE programme. There are 809 Part-time tutors, who are appointed to support the students through facilitating group tutorial sessions and seminars and individual support through workplace visits and feedback on completed assignments [40].

Programmes offered by the IEDE

- 3-year Diploma in Basic Education (Dip. Basic Ed)

- 3-year Diploma in Early Childhood Education (Dip. Early Childhood Ed)

- 2-year Bachelor of Education in Basic Education (B. Ed.) for Diploma in Basic Education Holders only

- 2-year Bachelor of Education in Early Childhood Education (B. Ed.) for Diploma in Early Childhood Education Holders only

- 3-year Diploma in Accounting Studies (Dip. Accounting)

- 3-year Diploma in Management Studies (Dip. Mgt. Std.)

- 2-year Bachelor of Business Administration in Accounting Studies (B. BA - Accounting)

- 2-year Bachelor of Business Administration in Human Resource Management (B. BA - HRM

Additionally, the following graduate programmes are also offered by the IEDE.

Master of Education in English, Master of Education in Mathematics, Master of Education in Science, Master of Education in Mentorship, Postgraduate Diploma in Teaching and Learning in Higher Education Institutions (PGDTLHEI) and Postgraduate Diploma in Education (PGDE): [40]

\section{Research Objectives}

This research focused largely on the four leading publicly funded Universities in Ghana known extensively for their Distance Education programmes, namely; The University of Ghana (UG), Kwame Nkrumah University of Science and Technology (KNUST), The University of Cape Coast (UCC) and the University of Education, Winneba (UEW). However, this paper makes specific reference to the University of Cape
Coast. The Centre for Continuing Education now College of Distance Education (CODE) was established by the University of Cape Coast in 1997 to provide opportunities predominantly, for teachers and other professionals to pursue higher education in addition totraining high calibre personnel for national development.

The question of interest is whether DE in Ghana has been effective since its inception; the contributions it has made towards improving quality and accessibility to Tertiary Education practice in Ghana and the realization of its intended mission; the benefits DE has provided to both students and employers (public and private) over the period; whether the targeted population essentially patronize DE and ultimately whether productivity in both the public and the private sectors of the economy has witnessed significant improvements. Especially with new graduates bringing into the market, enhanced human capital in terms of the competencies developed in the course of their Distance Education programmes.

\subsection{Justification}

The appropriateness of the CODE as the preference for the case study was primarily borne out of its diverse nature of programmes and the hugely successful patronage it has enjoyed over the years characterized by the steady rise in the number of students it admits and subsequently churns out each year. Moreover, the College of Distance Education (CODE) has positioned itself increasingly as a modern and attractive Distance Education prospect, reflected in its nationwide pursuit of a new generation of young recruits and the parity of esteem between DE and conventional face to face campus based programmes.

\subsection{Research Hypothesis}

The research hypothesis is the presence of statistically significant relationship between the effectiveness and the mode of delivery through DE in Ghana's higher education practice. In other words; Distance Education has not been effective in Higher Education practice in Ghana. It is believed that Distance education has accomplished its intended objectives in the Tertiary Education landscape and its introduction has seen massive improvement in productivity for the private and public sectors of the economy over the last couple of decades.

There are multiple indicators, intended to support the argument that Distance Education in Ghana has undeniably been effective since its inception.

\section{Methodology}

The main instrument used in this research work was design questionnaire. The data used for this research was primary data as secondary information was not obtainable on the variables mentioned in the specific objectives of this research.

The sampling procedure for selecting the sample for 
interviewing was stratified random sampling. Stratified random sampling is basically, categorizing a heterogeneous population into homogeneous subgroups called strata and the sample drawn either proportionately or disproportionately from each stratum. This probability sampling procedure was adopted because of the nature and size of the population. The population consisted of 1000 students who are assessing Distance Education from The College of Distance Education (CODE) of the UCC in various programmes across the academic spectrum scattered within the regions at designated locations known as "Study Centres" with different characteristics thus enabling this sampling procedure to be conveniently applied. The various programmes form the strata because each student on the DE programme could be assigned to only one programme (stratum). Proportionate stratification was used with sampling fraction of $\frac{n}{N}=\frac{400}{1000}=$ 0.4 to select the sample size from each stratum. This means that out of the 1000 students $(N=1000) 400(n=400)$ were desired for this study. This is indicative of the fact that with proportionate stratification, the sample size of each stratum (programme) is proportionate to the population size of the stratum. Thus the same sampling fraction was applicable to each stratum.

The data was analyzed using both descriptive and inferential statistics. Descriptive statistics such as tables and graph were used to display facts diagrammatically. Inferential statistics chi-square test of goodness-of -fit was used to specifically answer the research Hypothesis [13].

\section{Results and Discussions}

The results obtained from the interviews are presented in this phase of the research.

Table 1. Age Distribution.

\begin{tabular}{lllll}
\hline & Frequency & Percent & Valid Percent & Cumulative Percent \\
\hline $15-19$ & 10 & 2.5 & 2.5 & 2.5 \\
$20-24$ & 22 & 5.5 & 5.5 & 8.0 \\
$25-29$ & 104 & 26.0 & 26.0 & 34.0 \\
$30-34$ & 176 & 44.0 & 44.0 & 78.0 \\
$35-39$ & 48 & 12.0 & 12.0 & 90.0 \\
$40-44$ & 34 & 8.5 & 8.5 & 98.5 \\
$45-49$ & 6 & 1.5 & 1.5 & 100.0 \\
Total & 400 & 100.0 & 100.0 & \\
\hline
\end{tabular}

Table 1 illustrates the age category of the students who responded to the questionnaire. The two most dominant age groups were 30-34years (176 out of 400) and 25-29 years (104 out of 400) representing $44.4 \%$ and $26.0 \%$ respectively. The two age groups that were least represented were 45-49 (6 out of 400) and 15-19 (10 out of 400) constituting $1.5 \%$ and $2.5 \%$ of the total respondents correspondingly.

Table 2. This shows the Sex distribution of the respondents.

\begin{tabular}{lllll}
\hline & Frequency & Percent & Valid Percent & $\begin{array}{l}\text { Cumulative } \\
\text { Percent }\end{array}$ \\
\hline Male & 188 & 47.0 & 47.0 & 47.0 \\
Female & 212 & 53.0 & 53.0 & 100.0 \\
Total & 400 & 100.0 & 100.0 & \\
\hline
\end{tabular}

From table 2 it was observed that an overwhelming majority of the respondents were females representing $53.0 \%$ (212 out of 400) whiles the rest representing 47.0\% (188 out of 400) of the total respondents were of the opposite sex.

Figure 1 shows the Category of students targeted by DE programmes.

Table 3. Distribution of the Target Population for DE.

\begin{tabular}{lllll}
\hline & Frequency & Percent & $\begin{array}{l}\text { Valid } \\
\text { Percent }\end{array}$ & $\begin{array}{l}\text { Cumulative } \\
\text { Percent }\end{array}$ \\
\hline Workers & 165 & 82.5 & 82.5 & 82.5 \\
Non Workers & 35 & 17.5 & 17.5 & 100.0 \\
Total & 200 & 100.0 & 100.0 & \\
\hline
\end{tabular}

A PERCENTAGE ME CHART SHOWTNG TARGETED INDIVIDUALS FOR DISTANCES EDUCATION PROGRAMQME

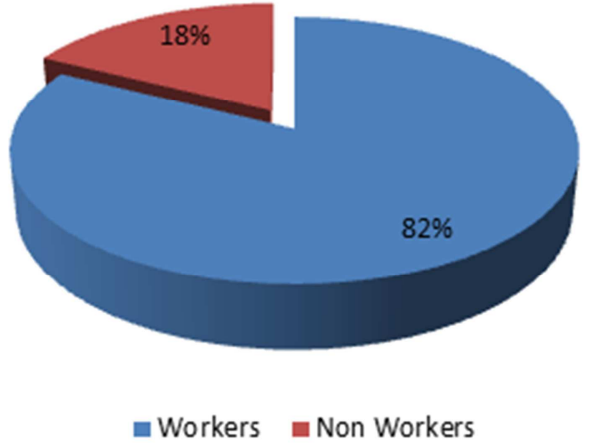

Fig. 1. Targeted Population for DE Programmes.

From the chart above it is evident that an overwhelming majority of the students (330 out of 400 ) forming $82 \%$ of those who patronize distance education programmes are workers whilst 70 out of 400 representing $18 \%$ of the total students who were interviewed are non-workers.

Table 4. Contribute to Improving Quality and Accessible Education in Ghana.

\begin{tabular}{lllll}
\hline & Frequency & Percent & Valid Percent & Cumulative Percent \\
\hline Yes & 326 & 81.5 & 81.5 & 81.5 \\
No & 74 & 18.5 & 18.5 & 100.0 \\
Total & 400 & 100.0 & 100.0 & \\
\hline
\end{tabular}

Table 4 illustrates the responses based on the contribution DE has made towards improving quality education in Ghana. A significant number of students (326 out of 400) constituting $81.5 \%$ of those accessing DE believed that it has made enormous contribution towards improving quality and accessible education in Ghana whilst a minority of the participants ( 74 out of 400 ) representing $18.5 \%$ maintain the assertion that DE has not made enough contribution towards improving quality and accessibility to education.

The benefits DE offers to both students and employers is also one of the focalpoints of this paper. Table 5 shows the responses obtained from the students who took part in the survey. 
Table 5. Benefits Derived From DE Programmes.

\begin{tabular}{ll}
\hline Benefits & Percentage (\%) \\
\hline Access to University Education & 74.0 \\
Improved Knowledge and Employee Efficiency & 55.5 \\
Cost Effectiveness & 46.0 \\
Convenience & 63.0 \\
Flexibility & 56.5 \\
\hline
\end{tabular}

It could be inferred from the table above that access to university education represented (74\%), convenience $(63 \%)$, flexibility $(56.5 \%)$ and improved knowledge and employee efficiency $(55.5 \%)$ are the foremost essential benefits DE offers to those who access DE programmes as individuals whilst industry benefits indirectly when the knowledge and skills-set of their employees are improved and significantly enhanced respectively through DE.

Figure 2 illustrates the views of the students who took part in the survey on whether productivity in the two sectors of the economy (private and public) has witnessed remarkable improvement with the participation of employees in Distance Education programmes.

ABAR CHART SHOWNG WHETHER PRODUCTIVTTY HAS IMPROVED IN BOTH PUBLIC AND PRIVATE SECTOR

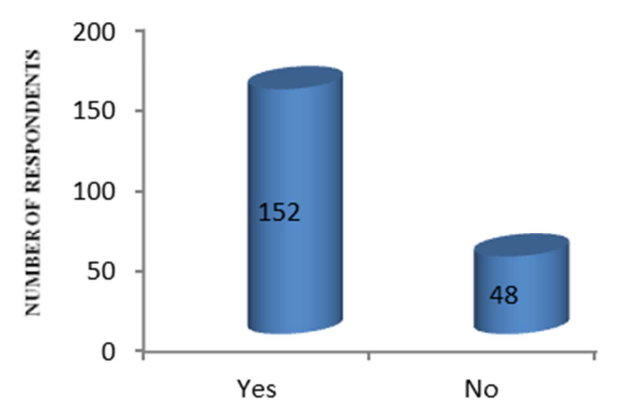

Fig. 2. A Bar Chart showing Productivity improvement.

It is evident from the chart above that an overwhelming number of respondents (304 out of 400) constituting $76.0 \%$ affirmed that Distance Education has significantly improved productivity in both public and private sectors of the economy of Ghana whilst the rest of the respondents of the survey (96 out of 400) representing $24.0 \%$ believed that productivity has seen no significant improvement with the introduction of Distance Education programmes.

The Hypothesis tested was $\mathrm{H}_{0}$ : Distance education has not been effective in the Ghana's Tertiary Education practice against the alternative $\mathrm{H}_{1}$ : Distance education has been effective in the Ghana's Tertiary Education practice.

The test was conducted at $5 \%(\alpha=0.05)$ level of significance. The condition under which the null hypothesis $\left(\mathrm{H}_{0}\right)$ is rejected is when $\chi_{\text {cal }}^{2}>\chi_{0.05,1}^{2}$.

Table 6. Test Statistics.

\begin{tabular}{ll}
\hline Has the programme been effective since its inception \\
\hline Chi-Square & $52.020^{\mathrm{a}}$ \\
df & 1 \\
\hline
\end{tabular}

From Table $6, \chi_{\text {cal }}^{2}$ is 52.020 and $\chi_{0.05,1}^{2}$ from the tables is 7.879 .

Since $\chi_{\text {cal }}^{2}>\chi_{0.05,1}^{2}$, that is $52.020>7.879, \mathrm{H}_{0}$ is rejected and $\mathrm{H}_{1}$ retained.

\section{Findings}

The findings of this study indicate that, majority of the target population who access DE programmes in Ghana are in the age brackets groups of $\{30-34\}$ years and $\{25-29\}$ years as clearly depicted in table 1 . It was also observed that persons within the age cohorts of $\{15-19\}$ years and $\{45-49\}$ years do not enroll in significant numbers in Distance Education programmes. Effectively, this suggests that individuals in the working class considerably patronize Distance Education programmes. A study by Gibson, 1998; 2003 [12]; Kirkwood et al, 2005 [22] concludes that a substantial proportion of distance learners continue to be working adults aged between twenty five and forty five who have busy established lives and are studying part-time to improve or upgrade their competences, professional skills and knowledge. This further lends credence to the assertion that employees constitute the main target group for the establishment of DE programmes.

As evident from the responses and in a study conducted by Thompson, Melody (1998) [33] in North America, it was empirically established that comparatively Distance Education programmes have more female patronage than their male counterparts. Eastmond (1995) [6] also cited a 1992 study which reported that women outnumbered men in New Zealand and Israel on DE programmes. This further supports the argument that, an overwhelming number of females in the working class for reasons mainly attributed to social and family commitments are unable to enroll as students on various campuses to pursue conventional college programmes. According to Von Prümer (2000) [34], traditional gender divisions of labour in most societies continue to make working women the primary care givers of children and relatives. These obligations, often deny them the opportunity to enroll in regular conventional face to face programmes. However, convenient access to DE provides them with a quality alternative. Hence the female dominance in DE programmes.

Moreover, DE programmes are aimed at training individuals who are full time employees with busy established schedules and therefore cannot access education directly on campuses of the institutions of their choice. The results obtained from the survey point to the fact that a considerable number of working adults patronize DE, signifying employees and their respective employers have confidence in DE and the objective of training workers through distance learning has been productively accomplished and a success story thus far.

Incidentally, one of the objectives of this study was to find out the extent to which Distance Education has contributed towards improving quality and accessible education in Ghana's higher education setup. The results 
showed that an overwhelming number of students accessing DE acknowledged that, it has indeed made immense contribution towards the realization of quality and accessible education over the last several years in the country's tertiary education setup. The extensive work done by Holmberg, B (2005) [14] concludes that DE is constantly being evaluated and has proven to be very effective in helping motivated and hard-working students reach their goals. Evidently, the picture emerging from the study reveals a similar conclusion in consonance with the findings of Phipps and Merisotis (1999) [29]; that the effectiveness of DE over the years cannot be overemphasized and it has undoubtedly fulfilled its avowed mandate of providing quality and accessible education for themajority of the working class.

The study also sought to determine the benefits individuals and corporate bodies derive from DE. The outcomes of the study revealed that, among the principal benefits ensuing from DE programmes are Access to University Education, Convenience, Flexibility and Improved knowledge and Employee efficiency. This means, as individuals gain access to convenient and flexible tertiary education whilst on the job, they acquire new knowledge, skills and competencies. Subsequently, this is reflected in improved efficiency and general work output in their respective job schedules by the immediate application of better working skills and competencies acquired in the course of their training. Bruce (1999) [3] writing on opportunities offered by DE comes to a similar conclusion.

Additionally, the study revealed that a significant number of the respondents $(76 \%)$ acknowledged that, DE has in essence improved productivity in both sectors of the economy over the last couple of decades. Malik et al. (2005) [24] opined that DE has the potential to impact all levels of education especially at the tertiary level, where the maximum benefits in terms of economic impact could be remarkably achieved.

The major Hypothesis of the study was; DE has not been effective in the Tertiary Education landscape. The study however, shows that DE over the years has been effective in the Higher Education practice since its re-introduction in the 1990s.

Table 7. DE Has Improved Productivity In Both Public And Private Sectors.

\begin{tabular}{lllll}
\hline & Frequency & Percent & Valid Percent & Cumulative Percent \\
\hline Yes & 304 & 76.0 & 76.0 & 76.0 \\
No & 96 & 24.0 & 24.0 & 100.0 \\
Total & 400 & 100.0 & 100.0 & \\
\hline
\end{tabular}

Table 8. The Effectiveness of Distance Education.

\begin{tabular}{lllll}
\hline & Frequency & Percent & Valid Percent & Cumulative Percent \\
\hline Yes & 302 & 75.5 & 75.5 & 75.5 \\
No & 98 & 24.5 & 24.5 & 100.0 \\
Total & 400 & 100.0 & 100.0 & \\
\hline
\end{tabular}

\section{Conclusion}

Distance education has come to stay and will continue to grow in Ghana's higher education practice. The major reason contributing to this growth is related essentially to the evergrowing need for an educated workforce, combined with financial burden and constraints of established tertiary educational institutions. DE offers life- long learning prospects to working adults with busy established lives and has also contributed significantly in educating a greater percentage of the population. Distance Education has become unarguably an important platform in the education enterprise in Ghana because it is cost effective and efficient. It also allows for independent learning by the female working adult due to their peculiar social and family commitments.

Understandably, if Ghana is to cope with the growing need for an educated workforce, distance education will continue to dominate the tertiary education landscape.

In conclusion, $\mathrm{DE}$ is no longer viewed as a marginal educational activity. Instead, it is regarded as a viable and an effective way of providing new opportunities and frontiers in higher education for countless number of the populace who otherwise would have had no access to tertiary education. Recent developments in ICTs are gradually erasing the lines between traditional and distance learners as more students now have the opportunity to work with emerging interactive technologies. The narrative, empirically supported by other scholars brings to the fore; the indispensable nature of distance education programmesin Ghana's higher education practice. The effectiveness of the programme is attested by the sheer number of graduates being churned out each year from DE programmes nationwide especially the CODE of the University of Cape Coast.

\section{References}

[1] Asabere, N. Y and Mends-Brew, E (2012) Distance Learning and Electronic Learning (e-Learning): Are they the same? An overview of Some Tertiary institutions In Ghana

[2] Barclay, M (2001) Introduction to Business Statistics

[3] Bruce, B. (1999). Education online: Learning anywhere, anytime. Journal of Adolescent and Adult Literacy, 42 (8), $662-665$.

[4] Collis B. A. (1996). Tele-Learning in a Digital World: The Future of Distance Learning, International Thomson.

[5] Dagger, D et al (2007) Service oriented e-learning platforms: from monolithic systems to flexible services,

[6] Eastwood, 1995. Outlooks and Opportunities in Blended and Distance Learning

[7] Eastwood, K. and Onken, M. "The Efficacy of Distance Learning in Affecting Change". WebNet World Conference 98, Association for the Advancement of Computing in Education, Orlando, November 1998.

[8] Falvo, D. A and Johnson, B. F (2007). The Use of Learning ManagementSystems in the United States. 
[9] Garrison, D. R. (1997). Computer conferencing: The postindustrial age of distance education. Open Learning, 12 (2), 3-11.

[10] Garrison, D. R. (2009). Implications of online and blended learning for the conceptual development and practice of distance education. The Journal of Distance Education, 23 (2). Retrieved

fromhttp://www.jofde.ca/index.php/jde/article/view/471/889.

[11] Gerhardt, L. A. (2005) Information Technology Based Higher Education and Training, ITHET 2005, 6th International Conference.

[12] Gibson, C. C. (1998b). The distance learner's academic selfconcept. In C. C. Gibson (Ed.), Distance learners in higher education: Institutional responses for quality outcomes (pp. 65-76). Madison, WI: Atwood.

[13] Gordor, B. K. and Howard, N. K. (2006). Introduction to Statistical Methods. Ghana Mathematics Group, Ghana.

[14] Holmberg, B. (2005). The Evolution, Principles and Practices of Distance Education, Bls-Verlagder: Oldenburg.

[15] Holmberg, B. 1995. Theory and practice of distance education, 2nd revised edition. London and New York: Routledge.

[16] Holmberg, B. 2003. Distance Education in Essence: An overview of theory and practice in the early twenty-first century 2 nd ed.

[17] Honeyman and Miller (1993). "Agriculture Distance Education: A valid Alternative for Higher Education".

[18] Hope, A and Guiton, P. (2006). Strategies for Sustainable Open and Distance Learning. IEEE Internet computing, vol 11

[19] Keegan, D. (1993 b). Reintegration of the teaching acts. In D. Keegan (Ed.), Theoretical principles of distance education. London and New York: Routledge

[20] Keegan, D. (Ed.) (1993 a). Theoretical principles of distance education. London and New York: Routledge.

[21] Keegan, D. J. (1990). Foundations of distance education. London and New York: Routledge.

[22] Kirkwood, A., and Price, L. (2005). Learners and Learning in the 21st Century: What do we know about students' attitudes and experiences of ICT that will help us design courses? Studies in Higher Education 30 (3), 257-274.

[23] Kwapong, O. A. T. F. (2010). Equitable Access: Information and Communication Technology for Open and Distance Learning. iUniverse, Inc., Bloomington New.

[24] Malik, N. A., Belawati, T., \& Baggaley, J. (2005). Framework of Collaborative Research and Development on Distance Learning Technology for Asia. Paper presented at the 19th Annual Conference, Association of Asian Open Universities, Jakarta, Indonesia. Retrieved June 9, 2007, from http://www.pandora-asia.org/downloads/05AAOU_MalBelBag.pdf

[25] Moore, M., Kearsley, (2005). Distance Education: a system view. Wadsworth: USA, 3rd Edition.
[26] National Council For Tertiary Education (NCTE) Report (2010)

[27] National Council for tertiary Education (NCTE), Ghana Report, 2006

[28] Onken, M., \& Eastwood, K. (1998). Is it possible to use distance learning to affect change in attitudes? The Third Annual TCC Conference: Online Instruction: Trends and Issues II, Honolulu, Hawaii (on-line), April 1998 On-line: http://leahi.kcc.hawaii.edu/org/tcon98/paper/eastwood.html

[29] Phipps, R., and Merisotis, J. (1999). What's the Difference? A review of Contemporary Research on the Effectiveness of Distance education in Higher Education. The institute for Higher Education policy.

[30] Ronald M. W. (2010). Introduction to Business Statistics, South-Western College Publications, 7TH Edition.

[31] Tau, Daniel R (2011). Open and Distance Learning Practices in Southern Africa: Collaborative Initiatives.

[32] Taylor, James C (2001). Fifth Generation Distance Education: A Sustainable Approach To Development.

[33] Thompson, M. M. (1998). Distance learners in higher education. In C. Campbell Gibson (Ed.), Distance learners in higher education: Institutional responses for quality outcomes. Madison, WI: Atwood Publishing, pp. 10-18)

[34] Von Prümmer, C. (2000). Women and Distance Education: Challenges and opportunities. New York: Routledge.

[35] Wulf, Katie (1996) "Training via the Internet: where are we?" Training \& Development.

[36] IDL, KNUST. (2015) http://www.idl.knust.edu.gh/pages/index.

[37] IDCE, UG (2006-2008) http://www.ug.edu.gh/icde/index1.php?

[38] IDCE, UG (2013) http://www.ug.edu.gh/icde/index1.php?

[39] UCC, (2006-2012) http://www.ucc.edu.gh/code/index1.

[40] IEDE, UEW (2012-2015) http://www.uew.edu.gh/iede/index.

[41] (https://en.wikipedia.org/wiki/Distance_education).

[42] http://www.pewinternet.org/ /media//Files/Reports/2011/PIPOnline-Learning.pdf

[43] http://www.nytimes.com/2012/07/17/education/consortiumof-colleges-takes-online-education-tonewlevel.html?_r=2\&hp

[44] http://www.nytimes.com/2012/07/17/education/consortiumof-colleges-takes-online-education-tonewlevel.html?_r=2\&hp

[45] http://www.insidehighered.com/news/2012/01/24/stanfordopen-course-instructors-spin-profit-company $\&$ http://www.insidehighered.com/news/2012/04/06/how-couldmitx-change-mit 